\title{
Luiz Gonzaga e alimentação sertaneja: as práticas alimentares representadas nas letras musicais
}

\author{
Luiz Gonzaga and Country Supply: feeding practices represented in musical lyrics \\ Luiz Gonzaga et Pays d'alimentation: les pratiques d'alimentation représentés dans \\ les paroles de chansons
}

\author{
Luiz Gonzaga y País de alimentación: prácticas de alimentación representados en las letras \\ musicales
}

\author{
Moacir Ribeiro Barreto Sobral* \\ (moacirsobral@gmail.com)
}

Recebido em 23/11/2013; revisado e aprovado em 15/08/2014; aceito em 20/09/2014

DOI: http:/ / dx.doi.org/10.1590/1518-70122015113

\begin{abstract}
Resumo: O cantor Luiz Gonzaga divulgou pelo Brasil os forrós e outros estilos musicais, ecoando as tristezas e os amores de um povo que ainda não tinha voz. O presente trabalho, de natureza qualitativa, apoiada na análise de conteúdo e nos estudos biográficos do cantor, objetiva identificar as letras das músicas cantadas por Gonzaga que contemplam representações da cultura nordestina, relativas a alimentação. As letras dessas músicas contemplam representações da alimentação, tratam questões essenciais à hospitalidade da cultura e vida do povo nordestino. Palavras-chave: Hospitalidade. Alimentação. Luiz Gonzaga.
\end{abstract}

Abstract: The singer Luiz Gonzaga released by Brazil's forró and other musical styles, echoing the sorrows and loves of a people who still had no voice. This study was qualitative, based on content analysis and biographical studies of the singer, aims to identify the lyrics of the songs sung by Gonzaga that include representations of northeastern culture, relative power. The lyrics of these songs include representations of power deal essential to hospitality culture and life of the northeastern people issues.

Key words: Hospitality. Food consumption. Luiz Gonzaga.

Résumé: Le chanteur Luiz Gonzaga publié par le Brésil de forró et d'autres styles musicaux, faisant écho aux peines et amours d'un peuple qui n'avait toujours pas de voix. Cette étude a été qualitative, basée sur l'analyse du contenu et des études biographiques de la chanteuse, vise à identifier les paroles des chansons chantées par Gonzague qui comprennent des représentations de la culture nord-est, la puissance relative. Les paroles de ces chansons sont des représentations de la puissance accord essentiel à la culture et à la vie des questions de personnes du nord hospitalité. Mots-clés: L’hospitalité. Alimentaire. Luiz Gonzaga.

Resumen: Luiz Gonzaga el catantante liberado por Brasil de forró y otros estilos musicales, haciendo eco de los dolores y amores de un pueblo que todavía no tenían voz. Este estudio fue de tipo cualitativo, basado en el análisis de contenido y los estudios biográficos de la cantante, tiene como objetivo identificar las letras de las canciones cantadas por Gonzaga, que incluyen representaciones de la cultura del noreste, el poder relativo. Las letras de estas canciones incluyen representaciones de reparto de energía esencial para la cultura de la hospitalidad y de la vida de los problemas de las personas del noreste.

Palabras clave: La hospitalidad. Alimentos. Luiz Gonzaga.

\section{Introdução}

O cantor e compositor popular brasileiro Luís [Lua] Gonzaga [Gonzagão] do Nascimento nasceu em Exu, município de Pernambuco, e recebeu de Humberto Teixeira o título de Rei do Baião no auge da sua carreira.

O primeiro músico a assumir sua origem nordestina, sempre trajado com chapéu de couro e acompanhado de sanfona, zabumba e triângulo, levava alegria às festas juninas e mostrava ao Brasil os forrós pé-deserra e outros ritmos ainda desconhecidos por todo o país, como o xote e o xaxado. As letras evidenciavam a pobreza, as dores e as injustiças presentes na sua região natal, ecoando as tristezas e os amores de um povo que ainda não tinha voz.

Muitos consideravam ainda no início de sua carreira, que Luiz Gonzaga tinha uma voz que não era adequada para o estilo musical da época, mas isso não o impediu de popularizar a música nordestina na década de 40 . No início de sua carreira, o cantor apostou em sua divulgação por meio da participação em shows de calouros, inicialmente tocando valsas e tangos. Porém, em virtude da solicitação de

*Universidade Anhembi Morumbi, São Paulo, SP, Brasil. 
alguns nordestinos que pediram a apresentação de uma música que lhes tocasse o coração, que rememorasse as histórias vivenciadas no nordeste, assim o cantor retomou o estilo musical de sua infância. "Pé de Serra" e "Vira e mexe" esses estilos que conquistaram não somente os estudantes, mas também a maior nota do programa de calouros de Ary Barroso (DREYFUS, 1996).

Luiz Gonzaga trouxe para si a missão de representar o povo nordestino, relatando em suas músicas suas alegrias e tristezas e contando para o Brasil as dificuldades climáticas e econômicas vivenciadas pelo povo sertanejo. Isso tudo em forma de poesia. Oriundo do folclórico município de Exu, descobriu na paisagem do interior do nordeste brasileiro o material necessário para produzir suas canções. Falecido em 1989, o artista ainda tem sua obra viva nas exposições de numerosos artistas.

Fundamentado na análise de conteúdo (BAUER, 2002), foram selecionadas seis letras cantadas ou compostas por Gonzaga, no universo de mais de setecentas canções. Procurou-se destacar músicas que possuem aderência à proposta de trabalho, selecionando canções que destacam os hábitos alimentares dos nordestinos. É a vivência de uma experiência que pressupõe solidariedade e a comensalidade, nesse caso tratada também como um fator social já que a organização da alimentação na vida cotidiana não se restringe aos aspectos biológico e ecológico.

A família nordestina constitui a temática recorrente das músicas cantadas por Luiz Gonzaga, sempre associada ao trabalho nas roças, à participação nas feiras livres - local onde vendem a colheita e compram mantimentos -, às refeições em família e ainda às festividades, como exemplo, a festa do milho, ou o mutirão para a construção de uma casa de barro e taipa, indicando laços festivos que são reafirmados nessas práticas.

A alimentação nordestina faz-se presente na sociabilidade. Muitos itens que compõem a mesa nordestina podem ser vistos em lugares de encontro, como as feiras de rua, como exemplo, na Feira de Caruaru, que são ressaltadas nas letras de Gonzaga. É possível perceber algumas peculiaridades dessa alimentação e das influências portuguesa, indígena e africana na cozinha sertaneja nas músicas, que é notoriamente uma cozinha representada pela simplicidade de seus pratos. Além de ter um padrão específico de etiqueta, a forte personalidade do sertanejo faz com que a tradição alimentar seja mantida através do tempo, a ponto de recusar a influência de hábitos alimentares de regiões próximas.

A fundamentação da alimentação nordestina encontra-se nas obras de Luiz Câmara Cascudo (2004), especialmente no livro "A história da alimentação no Brasil", em Gilberto Freyre (2002) no livro "Açúcar", e em Raul Lody, cujos livros abordam a alimentação no Brasil e no Nordeste.

Foram analisadas nas músicas de Gonzaga as categorias: comensalidade e alimentação, em que Gonzaga e seus compositores descrevem a vida familiar na roça, o cultivo e produção de alimentos e seus processos culinários na preparação de pratos típicos da região. Destacam-se na análise as músicas, "Frutos da terra" (1982), "Feijão com couve" (1946) e “Baião de Dois" (1977).

\section{Comensalidade e alimentação nas letras das músicas cantadas por Gonzaga}

A alimentação e a(s) cultura(s) nordestina(s) são temáticas recorrentes nas letras das músicas cantadas por Luiz Gonzaga ao longo de sua carreira. A análise dessas composições propostas neste estudo evidenciam tais temáticas fundamentadas no aporte teórico da hospitalidade.

Gonzaga cantou o sertão nordestino, evidenciou a religião e as crenças populares ali presentes, problematizou valores sociais, descreveu as feiras, mercados, bares e a alimentação cotidiana. Sua música também se ocupou de pessoas comuns, tais como repentistas, cronistas, vaqueiros, cangaceiros e as mulheres guerreiras do sertão, bem como de algumas personalidades da região, como seu ídolo Virgulino Ferreira, vulgo Lampião.

Ao longo de sua trajetória, Gonzaga gravou 248 músicas em 78 RPM, 38 músicas em 45 simples, 72 músicas em 45 duplos, 696 músicas em LPs 12 polegadas e 16 LPs de 10 polegadas, totalizando 1.063 músicas sem regravação (OLIVEIRA, 1991). Tais gravações foram realizadas em três gravadoras: a RCA, onde gravou a maioria de seus sucessos, a Odeon e a Copacabana. É autor de 53 
composições, interpretou sozinho 329 músicas e 243 com parceiros.

O procedimento metodológico pautouse primeiramente por uma observação do conjunto de composições cantadas por Luiz Gonzaga, seguiu-se a seleção das letras que se relacionam à alimentação, à(s) cultura(s) nordestina e a sua biografia. As letras foram analisadas por trechos, identificando em cada estrofe ou verso as manifestações socioculturais relativas ao Nordeste.

O corpus é uma seleção de materiais, "determinada de antemão pela analista, com (inevitável) arbitrariedade, e com a qual ele irá trabalhar" (Barthes, 1967, p. 96). Barthes, ao analisar textos, imagens música e outros materiais como significantes da vida social, estende a noção de corpus de um texto para qualquer outro material. Em seu opúsculo sobre os princípios da semiótica ele reduz as considerações sobre seleção a poucas páginas. A seleção parece menos importante que a análise, mas não pode ser separada dela. (BAUER, 2002, p. 44).

$\mathrm{O}$ corpus documental da presente na pesquisa é constituído por seis letras, cujas temáticas principais relacionam-se à biografia do cantor, nesse caso, à questão migratória e à comensalidade nordestina. A eleição dessas temáticas fundamenta-se no aporte teórico da hospitalidade, o que será explicitado adiante e, como salienta Bauer (2002), relatar o processo da seleção dos documentos é tão importante quanto a sua análise.

[...] a pesquisa qualitativa pode ser considerada como sendo uma estratégia de pesquisa independente, sem qualquer conexão funcional com o levantamento ou com outra pesquisa quantitativa independente. A pesquisa qualitativa é vista como um empreendimento autônomo de pesquisa, no contexto de um programa de pesquisa com uma série de diferentes projetos [...]. (BAUER, 2002, p. 27).

De abordagem qualitativa, a metodologia adotada apoia-se na análise de conteúdo. Segundo Bauer (2002), a análise de conteúdo embasa a interpretação do texto tanto qualitativa quanto quantitativa, e espera compreender o pensamento do sujeito através da escrita do seu texto. Sugere que todas as análises sejam categorizadas, para o que se faz necessária a criação de categorias que levam em consideração o objeto de pesquisa.
[...] a qualidade de uma análise de conteúdo depende de suas categorias. A categorização, gerar classes que reúnem um grupo de elementos da unidade de registro. As classes são batizadas a partir da correspondência entre a significação, alógica do senso comum e a orientação teórica do pesquisador. [...] ainda indica a possibilidade de uma categorização com categorias a priori, sugeridas pelo referencial teórico e com categorias a posteriori, elaboradas após a análise do material. (OLIVEIRA et al., 2003, p. 10).

$\mathrm{O}$ artista e compositor Luiz Gonzaga constitui o ator principal da pesquisa, por vezes é o protagonista das narrativas cantadas, cujas letras contemplam expressões culturais nordestinas. Canta o lugar onde nasceu, e o sertão constitui o elemento facilitador da sua construção musical. Como já ressaltado, a importância do povo e do lugar cultural possibilitou a identificação e a construção conjunta com seus compositores, do forró e do baião.

A intervenção dos seus principais compositores, como Humberto Teixeira e Zé Dantas, ambos migrantes oriundos da mesma região e residentes no Rio de Janeiro, facilitou a criação de composições com temáticas socioculturais e nordestinas. Na análise das letras composta por Gonzaga e seus compositores, percebe-se a junção da escrita poética lírica e popular.

Numa leitura atenta das canções de Luiz Gonzaga, e possível perceber a presença, de múltiplas vozes sociais dialogando, de forma que nas letras das canções a sua visão do nordeste não emerge sozinha, há presença de uma interação das suas palavras com as palavras de outros. As canções de Luiz Gonzaga possuem inter-relações dialogadas com outros discursos particulares como, discurso religioso, discurso político, discurso da seca, etc. (CORDEIRO, 2008, p. 62).

Cascudo (2004) aponta quatro tipologias na cozinha nordestina: a cozinha de litoral, baiana, maranhense e a mais cantada nas músicas de Luiz Gonzaga, a cozinha sertaneja. Privilegia-se neste artigo a cozinha sertaneja, que nasce no sertão nordestino, que abrange principalmente os estados de Pernambuco, Ceará, Rio Grande do Norte, Paraíba e Alagoas, em região de clima semiárido, cujas temperaturas oscilam entre $28^{\circ} \mathrm{C}$ e $44^{\circ} \mathrm{C}$, ambiente rústico e mata de caatinga. 
A palavra Sertão é de origem portuguesa, encontrada pela primeira vez relacionada ao Brasil na Carta de Pero Vaz de Caminha. É por essa categoria, que o Instituto Brasileiro de Geografia e Estatística (IBGE) designa o semiárido nordestino, adotada, em síntese, para indicar terras desconhecidas, longe do mar, onde o clima era muito diferente do habitado pelos portugueses. (FERREIRA, 2008, p. 93).

Segundo Lody (2008), no sertão pela manhã, antes do sertanejo ir para a roça, come manteiga do sertão, cuscuz de milho com leite, macaxeira, batata-doce, bode com farinha e café com rapadura. À noite, na volta do seu trabalho, junto com a família, alimenta-se de coalhada com rapadura, farinha com mandioca, queijo assado na brasa, tapioca com leite e café. O café da manhã e da noite, por muitas vezes, apresentam os mesmos pratos, ou seja, o mesmo padrão de consumo.

Já no seu almoço, o boiadeiro ou agricultor, ao se alimentar em casa, com a família ou simplesmente no pasto, costuma levar sua boia junto com ele, seus alimentos apresentam a mesma composição acima evidenciada, proporcionando-lhe energia para o trabalho pesado.

Alimentos como farinha, carne seca, rapadura e um dos principais, a palma forrageira, contribuem como principais produtos para sua dieta. Os animais também fazem parte da dieta como a galinha, bode e o boi. A vaca e o boi representam papéis importantes no sertão nordestino: a vaca na produção de leite, principal matéria prima para fabricação de manteiga, a manteiga de garrafa, queijo do sertão e queijo coalho, e o boi para produção da carne, como de carne de sol e jabá, ambas desidratadas pelo sal que ajuda a conservar o alimento e também a modificar da sua estrutura e sabor.

As carnes desidratadas foram utilizadas no Brasil antes mesmo da colonização. A primeira técnica foi o moquém, em que o indígena defumava e secava as carnes de caça, para terem mais tempo de vida. Fernandes (2007, p. 38) relata esta estratégia:

Enterram profundamente no chão quatro forquilhas de pau, enquadradas à distância de três pés e à altura de dois pés e meio; sobre ela assentam varas com uma polegada ou dois dedos de distância uma da outra, formando uma grelha de madeira [...] nele colocam a carne cortada em pedaços, acendendo um fogo lento por baixo, revirando de quarto em quarto de hora até que esteja bem assada. Como não salgam suas viandas para guardá-las, como nós fazemos, esse é o único meio de conservá-las.

Outra técnica utilizada até hoje é a salga das carnes, técnica introduzida pelos portugueses, já que os índios não utilizavam sal. Com ajuda desse processo que se originou a carne seca, carne do sol, charque, entre outros produtos que utilizam a salga em seu processo de fabricação. As carnes salgadas são muito utilizadas nas viagens dos vaqueiros e cangaceiros no nordeste, junto com a farinha de mandioca e a rapadura. É comum notar no sertão nordestino vaqueiros conservando as carnes desidratadas por baixo da sela do cavalo, entre um couro do animal e a sela, deixando-a mais macia. Ao mesmo tempo nas longas viagens com tempo curto, os vaqueiros e cangaceiros faziam a sua refeição, em cima da sela do cavalo em movimento, no máximo jogavam um pouco de manteiga de garrafa para hidratá-las e dar mais sabor ao alimento, às vezes também, quando tinham, junto com a carne comiam farinha para dar a sensação de satisfeitos mais rapidamente.

No sertão o sol ajuda a combinar sobras de carnes e peixes [...] carnes do sertão ou de sol, chegam a pratos importantes, como Maria-isabel, [...] Sertão, terra de produtos que vêm do gado leiteiro, formando cardápios que assumem valores nutritivos. Coalhadas, manteigas, queijo de coalho, queijo manteiga, para diferentes usos, que vão do café da manhã com cuscuz de milho e leite de coco [...] Trajetória do cangaço, dos vaqueiros, das lutas e conquista; da fé em santos inventados em de místicos salvadores. Desejos messiânicos de viver vidas além da terra; terra tão dura e seca. O cabra é forte, cabra danado, cabra de engenho, cabra da peste, cabra macho, sim sinhô. (LODY, 2010, p. 20).

A manteiga de garrafa, também conhecida no nordeste como manteiga da terra ou manteiga do sertão, é muito utilizada pelo sertanejo em sua cozinha, na cocção de alimentos. Sempre disposta na mesa, utilizada como tempero em pratos tradicionais. Fora da cozinha se apresenta amarrada nas cinturas dos cangaceiros e vaqueiros, que a utilizam em suas viagens para hidratar e dar sabor 
às carnes desidratadas, que se localizam em baixo das selas de seus cavalos.

Segundo Cascudo (2009), os cangaceiros engarrafavam as manteigas para facilitar a alimentação quando estivessem em cima dos cavalos, assim não parando a viagem, facilitando a alimentação; isso também era utilizado para engarrafar as farinhas de mandioca. Nesse mesmo livro identifica Virgulino, o Lampião, como possível inventor da manteiga de garrafa. O cangaceiro que viveu no sertão nordestino levava consigo culturas e costumes de outras cidades, colocando em circulação diferentes culturas.

No nordeste do Brasil, a manteiga de garrafa é obtida, entre outras maneiras, da seguinte forma: o leite é levado a coalhar, separa-se o soro do creme que se forma, o qual é batido ligeiramente para ficar consistente - ponto intermediário da manteiga; leva-se então ao fogo brando. Quando a "borra" começa a dourar retira-se do fogo e coa-se em seguida. O líquido resultante é a manteiga da garrafa. Ou então, a massa do leite fermentado com coalho animal é levada à cocção, geralmente em fogão a lenha: deve ser levada a dourar, e a continuidade do cozimento desprende o que virá a ser a manteiga de garrafa. Ela leva esse nome por ser comercializada em garrafas. Não pode ser utilizada como fritura, sendo ideal na finalização de pratos de legumes, tapioca e como acompanhamentos da carne do sol. (BARRETO, 2000, p. 249).

A alimentação sertaneja se familiariza com o ambiente e seu povo. Vimos que o cardápio do sertão, diferentemente do restante do nordeste, é mais seco, com sabores e preparações mais simples e rústicas.

A terra seca que se cultiva produz muito pouco ou, às vezes, nada. A grande ligação do animal com o nordestino é evidenciada através da ajuda dele na plantação e alimentação da sua família. No caso da vaca, o leite se transforma em vários subprodutos para sobrevivência e economia regional.

A análise das músicas foi realizada com o intuito de refletir sobre a hospitalidade e comensalidade presentes nas músicas cantadas por Luiz Gonzaga, destacando também o nordeste cantado na visão dos compositores e do próprio cantor.

A linguagem utilizada por Gonzaga assemelha-se à forma de manifestação regional, em que ele apresenta a oralidade que chegava mais perto da fala do homem nordestino. Segundo Albuquerque (2001), o "falar nordestino" constitui uma língua e sotaques imaginários, que se modificam com o passar dos tempos e por região do Nordeste. Nesse caso, cada região ou cidade desenvolve uma linguagem que se entende como uma variação linguística e não dialetos.

Para fundamentá-la, realizaram-se pesquisas sobre pratos típicos, ingredientes, colheita, preparação do alimento nas casas de sertanejo e o comer juntos, nesse sentido os indicadores dessa categoria são: alimentação e comensalidade. Na Categoria alimentação se analisa, nas letras cantadas por Gonzaga, a identificação de pratos regionais e ingredientes associados à cultura e identidade nordestina; já em comensalidade, se analisa a colheita desse alimento, preparação do alimento e o comer juntos.

Além de cantar e compor músicas sobre a realidade nordestina, Gonzaga insere nessas canções parte da sua história e da sua identidade, retratos do que vivenciou na sua rotina e, consequentemente, evidencia representações de suas raízes. A música "Feira de Caruaru" (1957), uma das mais importantes cantada por Gonzaga, demonstra a variedade de ingredientes e produtos encontrados lá.

A feira de Caruaru/ Faz gosto da gente ver/ De tudo que há no mundo/ Nela tem pra vender/ Na feira de Caruaru/ Tem massa de mandioca/ Batata assada/ Tem ovo cru/ Banana, laranja e manga/ Batata doce, queijo e caju/ Cenoura, jabuticaba,/ Guiné, galinha,/ Pato e peru/ Tem bode, carneiro e porco/ Se duvidar isso é cururu / Tem cesto, balaio, corda/ Tamanco, greia, tem boi tatu/ Tem fumo, tem tabaqueiro/ Tem tudo e chifre/ De boi zebu/ Caneco, arcoviteiro/ Peneira, boi/ Mel de uruçu/ Tem carça de arvorada/ Qué pra matuto/ Não andar nu/ Na feira de Caruaru/ Tem coisa pra gente ver/ De tudo que há no mundo/ Nela tem pra vender/ Na feira de Caruaru/ Tem rede, tem baleeira,/ Mó de menino/ Caçar nhandu/ Maxixe, cebola verde,/ Tomate, coentro,/ Côco e xuxu/ Armoço feito na corda,/ Pirão mexido/ Que nem angu,/ Mobília de tamborete/ Feita de tronco de mulungu/ Tem louça,/ tem ferro véio,/ Sorvete de raspa/ Que faz jaú/ Gelado, caldo de cana/ Fruta de parme/ E mandacaru/ Boneco de vitalino/ Que são conhecido/ Inté no Sul,/ De tudo que há no 
mundo/ Tem na feira de Caruaru/ A feira de Caruaru. (ALMEIDA, 1957).

Na letra composta por Onildo Almeida e cantada por Luiz Gonzaga, é demonstrada a riqueza que a feira tem nos ingredientes regionais comercializados e usados no preparo de pratos nas cozinhas de casas e restaurantes da região. Ingredientes como carde do sol, carne seca, macaxeira, farinha, tapioca, frutas típicas e muito mais. A letra da música também enfatiza que tudo que há no mundo se encontra lá, ou seja, os autores demonstram a grande variedade de itens encontrados na feira. Além de alimentação e pratos regionais, ressaltam a importância do artesão de brinquedos, móveis e de decoração regional feita de barro, como por exemplo, os bonecos de Vitalino produzidos e vendidos na própria feira.

Esta terra dá de tudo/ Que se possa imaginar/ Sapoti, jaboticaba/ Mangaba, maracujá/ Cajá, manga, murici/ Cana caiana, juá/ Graviola, umbu, pitomba/ Araticum, araçá/ Engenho Velho ô, canavial/ Favo de mel no meu quintal/ O fruto bom dá no tempo/ No pé pra gente tirar/ Quem colhe fora do tempo/ Não sabe o que o tempo dá/ Beber a água na fonte/ Ver o dia clarear/ Jogar o corpo na areia/ Ouvir as ondas do mar/ Engenho Velho ô, carnaval/ Favo de mel, no meu quintal. (FEIRA, 1982).

A música, "Frutos da terra" (1982) cantada por Gonzaga valoriza os frutos típicos do nordeste brasileiro, como cajá, mangaba, pitomba, graviola, manga. O cantor demonstra no seu histórico uma intensa preocupação em não perder suas referências originais, advindas da sua terra de origem, e a necessidade de ser porta voz de seu povo, divulgando para o Brasil e o mundo os hábitos e frutos da região nordeste. Além de valorizar os frutos e a terra produtiva, a música também tem um intuito de levar ao nordestino retirante do sudeste do Brasil, informações sobre a sua terra e o poder que ela ainda tem de gerar frutos, nas fazendas ou no quintal das casas dos nordestinos demonstrando a valorização das frutas regionais.

Ai que será?/ Tenho pratando/ Muita côve no quinta/ Ai o que será?/ Feijão com côve/ Que talento pode dá? \} bis/ Cadê a banha?/ Pra panela refogá/ Cadê açúcar?/ Pro café açucará/ Cadê manteiga?/ Leite e pão/ Onde é que tá? / Cadê o lombo?/ Cadê carne de jabá?/ Já tou cansado/ De escutá o doutor falá/ Que quarqué dia/ As coisa tem que melhorá/ Sem alimento/ Num se pode trabaiá/ Por que será?/ Feijão com côve/ Que talento pode dá? (GONZAGA; PORTELLA, 1946).

Baião intitulado "Feijão com Covê", composto por Luiz Gonzaga e José Portella, ambos os compositores apresentam nessa música, produtos típicos da alimentação no sertão nordestino, valorizando os ingredientes, mas ao mesmo tempo questiona a falta deles. Apresenta as dificuldades do nordestino com a seca mostra a preocupação com a falta de alimento. Incorpora os problemas do povo e as falsas promessas feitas pelos políticos, que fazem promessas de fartura de alimentos no nordeste que nunca chegam. Gonzaga critica os políticos usando alimentos típicos da sua região, e denuncia a miséria e o cansaço do seu povo no nordeste. O Sertão deixa de ser um lugar, oportuno e trona-se um mundo, abandonado pelas autoridades, de tristeza e miséria, de um povo cansado da pobreza.

Capitão que moda é essa, deixe a tripa e a cuié/ Home não vai na/ cozinha, que é lugá só de mulhé/ Vô juntá feijão de corda, numa panela de arroz/ Capitão vai já pra sala, que hoje têm baião de dois/ $\mathrm{Ai}$, ai ai, ó baião que bom tu sois/ Se o baião é bom sozinho, que dirá baião de dois / Se o baião é bom sozinho,/ que dirá baião de dois/ Ai ai, baião de dois, ai ai, baião de dois/ Capitão que moda é essa, deixe a tripa e a cuié/ Home não vai na/ cozinha, que é lugá só de mulhé/ Vô juntá feijão de corda, numa panela de arroz/ Capitão vai já pra sala, que hoje têm baião de dois/ Ai, ai ai, ó baião que bom tu sois/ Se o baião é bom sozinho, que dirá baião de dois / Se o baião é bom sozinho, que dirá baião de dois/ Ai ai, baião de dois, ai ai, baião de dois. (GONZAGA; TEIXEIRA, 1977).

Baião intitulado "Baião de Dois", composta por Luiz Gonzaga e Humberto Teixeira. A música foi composta em homenagem a um dos maiores clássicos da culinária regional nordestina e um dos mais consumidos. Ao mesmo tempo faz também uma homenagem as mulheres cozinheira da região nordeste. Segundo Fernandes (2001), o baião de dois é um prato de origem simples feito à base das sobras de feijão e arroz, ao longo dos tempos foi sendo adaptado com pedaços de carnes secas, queijo coalho, manteiga de garrafa e linguiça. 
Ôi pisa o milho, penerô xerém/ Ôi pisa o milho, penerô xerém/ Eu num vou criar galinha/ Pra dar pinto pra ninguém \} bis/ Na minha terra/ Dá de tudo que plantar/ O Brasil dá tanta coisa/ Que eu num posso decorar/ Dona Chiquinha/ Bote o milho pra pilar/ Pro angu, pra canjiquinha/ Pro xerém, pro munguzá/ Só passa fome/ Quem não sabe trabalhar/ Essa vida é muito boa/ Pra quem sabe aproveitar/ Pego na peneira/ Me dano a sacolejar/ De um lado fica o xerém/ Do outro sai o fubá/ Saculeja, saculeja, saculeja, já \} bis/ Penerô xerém. (GONZAGA; LIMA, 1945).

Baião intitulado "Penerô Xerém" composta por Luiz Gonzaga e Miguel Lima. Apresenta o Xerém como subproduto do milho, utilizado para alimentação das granjas de galinhas e para a produção de pratos típicos da culinária nordestina. Do milho retiramos vários subprodutos usados na culinária nordestina, Gonzaga apresenta na música alguns pratos regionais, como o angu, canjiquinha e munguzá.

Segundo Araújo (2009), o milho tem grande presença na alimentação humana e animal, pelas suas características nutricionais e grande fonte energética. Existem mais de 600 derivados do milho e destes 500 destinam-se para consumo humano, como: farinha de milho, xerém, canjiquinha, óleo. São utilizados na culinária brasileira, tendo participação efetiva de várias preparações cuscuz, polenta, canjica, pamonha, pipoca entre outros pratos da culinária regional.

Eu sou do Norte/ Rumei para São Paulo/ Fui mudar de sorte/ Com o fole na mão/ Comi de tudo/ Comida italiana/ Bife parmegiana/ Canelão de macarrão/ Provei também/ A tal de passarela/ Bebi da caipirinha/ E vinho de garrafão/ Mas eu confesso/ Não é por ser de lá/ Cana pernambucana/É a maior, meu irmão/ Oxente!/ Quando falo, não retruco/ Oxente!/ Cana só de Pernambuco \} bis. (GONZAGA; SIMOM, 1954).

Forro intitulado "Cana Só de Pernambuco", composto por Luiz Gonzaga e Victor Simon. Apresenta a sua chegada a cidade de São Paulo e aproveita a vida gastronomia da culinária paulistana. A influência italiana na cozinha paulista na década de 50 e a regional mostrando a caipirinha. Mas sente saudades da sua cachaça pernambucana. Gonzaga fala em entrevista a Dreyfus (1996), sobre a particularidade em cada nordestino com sua cachaça, normalmente um bom nordestino toma a cachaça produzida em sua terra, fala "cachaça e quem nem filho e mulher, cada um tem a sua". Em Pernambuco existe o museu da cachaça com mais de oito mil rótulos, só da cidade de Pernambuco.

\section{Considerações finais}

As canções de Luiz Gonzaga representam a cultura nordestina, evidenciam personagens, como o sertanejo, o migrante nordestino, o vaqueiro, os cangaceiros, a mulher guerreira etc. Além desses personagens Gonzaga canta o ambiente e o espaço cultural onde se desenvolvem estas histórias como: as casas de taipa, o sertão, as feiras, os mercados, a caatinga entre outros lugares importantes. Nas letras escritas por ele mesmo e por seus compositores, evidenciam a cultura nordestina e, sobretudo reconstroem a cultura a partir de sentimentos pessoais vividos por ele ou por seu povo.

Gonzaga foi um dos grandes difusores da cultura e identidade nordestina no Brasil e, com muito esforço em seu trabalho, sofrendo preconceitos da sociedade da época conseguiu quebrar barreiras, construir seu próprio ritmo, tornando-se um dos maiores cantores da atualidade. Criou seu próprio estilo, assumiu o papel de artista social, apresentandose com roupas e chapéus de cangaceiro que lembrava Lampião, também registradas e legadas à posteridade na capa dos discos. Gonzaga assumiu este estilo primeiramente para ficar mais perto do seu povo e quebrar a barreira que os separava quando usava terno e gravata nos shows.

A comensalidade e alimentação encontram-se em várias canções, pois Gonzaga adorava comer todo e qualquer tipo de comida, embora manifestasse sua preferência pela cozinha nordestina. Dreyfus (1996) aponta que o cantor nunca se alimentava se sentasse sozinho em uma mesa, seguindo os ensinamentos religiosos e paternais sempre compartilhava a mesa com alguém. Mesmo quando entrava sozinho em bares de outras cidades, sentava-se com pessoas desconhecidas e partilhava o alimento com elas, ou às vezes se acomodava no balcão e fazia sua refeição conversando com o atendente. Nas 
músicas como: "Feijão com Covê (1946)", "Baião de Dois" (1977), "Frutos da Terra (1982)" entre outras, são apresentados produtos e pratos típicos da região nordeste, ao mesmo tempo em que descreve métodos de produção e ingredientes, aparece também nas letras o agradecimento à fauna e flora por terem lhe concebido estes produtos naturais, aos animais e a terra que estão sempre presentes na vida do sertanejo, no seu trabalho, na colheita e na sua alimentação, dando o sustento à família.

Foram encontradas na análise alimentos e produtos, típicos da alimentação diária do nordestino, como manteiga de garrafa, carne seca, farinha, milho e feijão. Produtos que fazem parte da cesta básica popular.

Com todo seu esforço e trabalho, Gonzaga consegue ser um artista de renome nacional e internacional, divulgando através de suas músicas a cultura nordestina a partir de um estilo próprio. O seu povo e sua família foram fatores incentivadores para Gonzaga para que ele representasse a música popular do Nordeste. Temos que agradecer aos esforços e criações de ritmos como xaxado, baião, forró que fazem a alegria do nordeste e do povo brasileiro até hoje.

Sou um artista feliz, muito feliz, com o dom de unir o povo, só cuido de unir o povo, e nunca se esqueça do povão.

Luiz Gonzaga

\section{Referências}

Fontes musicais

ALMEIDA. A Feira de Caruaru. 78 RPM, RCA Rio de Janeiro, 1957.

FEIRA. Frutos da terra. LP: Eterno Cantador, RCA Rio de Janeiro, 1982.
GONZAGA; LIMA. Penerô Xerém. 78 RPM, RCA Rio de Janeiro, 1945.

GONZAGA; PORTELLA. Feijão com Covê. 78 RPM, RCA Rio de Janeiro, 1946.

GONZAGA; SIMOM. Cana só de Pernambuco. 78 RPM, RCA Rio de Janeiro, 1954.

GONZAGA; TEIXEIRA. Baião de Dois. LP: Chá Cutuba, RCA Rio de Janeiro, 1977.

Artigos, dissertações, livros:

ARAÚJO, W. M. Alquimia dos alimentos. Brasília: SenacDF, 2009.

ALBUQUERQUE, D. M. A invenção do Nordeste e outras artes. São Paulo: Cortez, 2001.

BARRETO, R. L. Passaporte para o sabor: tecnologias para eleboração de cardápios. São Paulo: Senac, 2000.

BAUER, M. W. Pesquisa qualitativa com texto, imagem e som . Petrópolis, RJ: Vozes, 2002. Global, 2004. História da alimentação no Brasil. São Paulo: Viajando o sertão. São Paulo: Global, 2009.

CORDEIRO, B. S. As canções de Luiz Gonzaga sob o olhar da análise crítica do discurso (ACD). 2008. Dissertação (Mestrado em Ciências da Linguagem) - Universidade Católica de Pernambuco - UNICAP, Recife, PE, 2008.

DREYFUS, D. Vida de viajante: a saga de Luiz Gonzaga. São Paulo: Ed. 34, 1996.

FERREIRA, L. D. Diálogos em ambientes e sociedade no Brasil . São Paulo: AMPPAS, 2008. (Coleção Cidadania e Meio Ambiente ).

FREYRE, G. Açúcar: uma sociologia do doce, com receitas de bolos e doces do nordeste. São Paulo: Companhia das Letras, 2002.

FERNANDES, C. Viagem gastronômica através do Brasil. São Paulo: Senac, 2001.

LODY, R. Brasil bom de boca: temas da antropologia da alimentação. São Paulo: Senac, 2008.

Culinária nordestina: o encontro do mar e sertão. Rio de Janeiro: Senac, 2010.

OLIVEIRA, E. D.; ENS, R. T.; ANDRADE, D. B.; MUSSIS, C. R. Análise de conteúdo e pesquisa na área da educação. Revista Diálogo Educacional, Curitiba, PR, v. 4, n. 9, p. 1-17, maio/ago. 2003.

OLIVEIRA, G. Luiz Gonzaga: o matuto que conquistou o mundo. Recife: Comunicarte, 1991. 